\title{
A dual-inexact fuzzy stochastic model for water resources management and non-point source pollution mitigation under multiple uncertainties
}

\author{
C. Dong ${ }^{1}$, Q. Tan ${ }^{1,3}$, G.-H. Huang ${ }^{1}$, and Y.-P. Cai ${ }^{2,3}$ \\ ${ }^{1}$ MOE Key Laboratory of Regional Energy and Environmental Systems Optimization, Resources and Environmental \\ Research Academy, North China Electric Power University, Beijing 102206, China \\ ${ }^{2}$ State Key Laboratory of Water Environment Simulation, School of Environment, Beijing Normal University, \\ Beijing 100875, China \\ ${ }^{3}$ Institute for Energy, Environment and Sustainable Communities, University of Regina, Regina S4S 7H9, Canada \\ Correspondence to: Y.-P. Cai (yanpeng.cai@bnu.edu.cn) and Q. Tan (tanqian@iseis.org)
}

Received: 7 December 2013 - Published in Hydrol. Earth Syst. Sci. Discuss.: 20 January 2014

Revised: - Accepted: 19 March 2014 - Published: 19 May 2014

\begin{abstract}
In this research, a dual-inexact fuzzy stochastic programming (DIFSP) method was developed for supporting the planning of water and farmland use management system considering the non-point source pollution mitigation under uncertainty. The random boundary interval (RBI) was incorporated into DIFSP through integrating fuzzy linear programming (FLP) and chance-constrained programming (CCP) approaches within an interval linear programming (ILP) framework. This developed method could effectively tackle the uncertainties expressed as intervals and fuzzy sets. Moreover, the lower and upper bounds of RBI are continuous random variables, and the correlation existing between the lower and upper bounds can be tackled in RBI through the joint probability distribution function. And thus the subjectivity of decision making is greatly reduced, enhancing the stability and robustness of obtained solutions. The proposed method was then applied to solve a water and farmland use planning model (WFUPM) with non-point source pollution mitigation. The generated results could provide decision makers with detailed water supply-demand schemes involving diversified water-related activities under preferred satisfaction degrees. These useful solutions could allow more in-depth analyses of the trade-offs between humans and environment, as well as those between system optimality and reliability. In addition, comparative analyses on the solutions obtained from ICCP (Interval chance-constraints program-
\end{abstract}

ming) and DIFSP demonstrated the higher application of this developed approach for supporting the water and farmland use system planning.

\section{Introduction}

Due to population growth, ongoing urbanization, industrialization and the intensification of agriculture, water and land demands are increasing globally, while the availability and quality of water resources and farmland are decreasing and non-point source pollution sharpening. These phenomena often cause a reduction in environmental quality and endanger sustainable development (Sessa, 2007). Thus, effective water resource and farmland use planning with non-point source pollution mitigation is necessary for ensuring economic and environmental welfare of regional populations (Ray et al., 2012; Mehta et al., 2013).

Previously, plenty of modeling technologies were applied to water resources and farmland use system planning with non-point source pollution mitigation (Satti et al., 2004; Chen et al., 2005; Riquelme and Ramos, 2005; Victoria et al., 2005; Kondilia and Kaldellis, 2006; Gregory et al., 2006; Khare et al., 2007; Castelletti et al., 2008; Qin et al., 2011; Mahmoud et al., 2011; Deviney Jr. et al., 2012; Zarghami and Hajykazemian, 2013; Canter et al., 2014). For example, Satti et al. (2004) used the GIS-based water resources 
and agricultural permitting and planning system to simulate the effect of climate, soil, and crop parameters on crop irrigation requirements. Chen et al. (2005) established forcestate-response (DSR) dynamic strategy planning procedure to assist responsible authorities in obtaining alternatives of sustainable top river basin land use management. Riquelme and Ramos (2005) built up a geographic information system (GIS) on vine growing for supporting decision-making processes related to land and water management in CastillaLa Mancha, Spain. Victoria et al. (2005) adopted modeling tools, ISAREG model and SAGBAH model, to solve multi-scale problems with irrigation water uses and nonpoint source pollution in basins. Qin et al. (2011) proposed a system dynamics and water environmental model to operate the integrated socio-economic and water management system in a rapidly urbanizing catchment. Mehta et al. (2013) developed integrated water resources management models using the water evaluation and planning decision support system, for three towns in the Lake Victoria region. Zarghami and Hajykazemian (2013) proposed a new optimization algorithm by coupling the mutation process to the particle swarm optimization, which was successfully applied to the urban water resources management with a non-point source pollution problem for Tabriz, Iran.

However, effective planning for water resource and farmland use management with non-point source pollution mitigation is actually complicated with a variety of uncertainties and dynamics. For example, intricate interactions exist between various subsystems (such as economy, ecoenvironment, society, administration, etc.), which will inevitably produce a variety of uncertainties. Moreover, subjective judgments obtained from experts and stakeholders also exert significant impacts on data acquisition and system reliability. These complexities lead to the difficulties in solving the resulted uncertain optimization problems (Azaiez et al., 2005; Sethi et al., 2006; Tan et al., 2011; Bender and Simonovic, 2000; Guo et al., 2010; Qin et al., 2007; Lu et al., 2012; Huang et al., 2012; Zhang et al., 2009; Gu et al., 2013; Dessai and Hulme, 2007; Cai et al., 2011, 2012; Li et al., 2013). Nowadays, the stochastic linear programming (SLP) and interval linear programming (ILP) have become two of the most effective optimization approaches, especially the chance-constraints programming (CCP). For instance, Azaiez et al. (2005) tackled the uncertainties in inflows through adopting chance constraints and penalties of failure for optimal multi-period operation of a multi-reservoir system. And in 2006, Sethi et al. (2006) developed deterministic linear programming (DLP) and chance-constrained linear programming (CCLP) models to allocate available land and water resources optimally on seasonal basis. Tan et al. (2011) developed a radial interval chance-constrained programming (RICCP) approach for supporting source-oriented non-point source pollution control under uncertainty. Another useful method handling uncertainties existing in water resources and farmland use management is based on fuzzy set theory. Bender and Simonovic (2000) applied a fuzzy compromise approach into water resource systems planning of the Tisza River. Qin et al. (2007) developed an intervalfuzzy nonlinear programming (IFNP) model for water quality management under uncertainty.

In reality, a high degree of uncertainty may exist among some parameters and coefficients of related water resources and farmland use management models. For example, the availabilities of various water resources are sensitive to geographical conditions and climate, technology selection and utilization efficiency, as well as water-saving consciousness, causing difficulties to related data acquisition, even the determination of interval numbers, when the lower and upper bounds are correlated. In the past decades, little work has been conducted to handle this type of uncertainty (dual uncertainty) existing in the processes of water and farmland use planning, which might result in missed information and thus impractical decision support (Cao et al., 2010). Therefore, in this study, a concept of random boundary interval (RBI) will be introduced to reflect such dual uncertainty. Specifically, the lower and upper bounds of RBI are continuous random variables, and the distribution information can be incorporated into the model. And, moreover, correlation existing between the lower and upper bounds can be tackled in RBI through the joint probability distribution function.

Finally, the proposed RBI theory and joint probability distribution will be integrated with ILP, CCP, and FLP technologies, leading to a dual-inexact fuzzy stochastic programming (DIFSP) method. Such an approach can tackle uncertainties expressed as interval numbers with known upper and lower bounds, fuzzy sets, as well as RBI. Due to the consideration of the intersection between lower and upper bounds, the robustness of the developed model could be enhanced. Then, this method will be applied to a water and farmland use planning model (WFUPM) with non-point source pollution mitigation for solving practical problems. And then many useful results will be generated, covering farmland use arrangement, water allocations among various consumers, resources supplies, and water pollution control under various water supply conditions and system reliabilities. The tradeoffs between system benefit and failure risks can be balanced through the use of probability of constraint violations and satisfaction degrees. In addition, the solutions obtained through the existing ICCP method and the DIFSP approach proposed in this study will be compared to demonstrate how DIFSP would become improved upon ICCP in the planning of a water and farmland use system. 


\section{Methodology}

\subsection{The concept of RBI}

In many practical problems, the lower and upper bounds of the right-hand sides can rarely be acquired as deterministic values. Instead, the obtained data can be presented as a random boundary interval (RBI) with its lower and upper bounds being random variables (Cao et al., 2010). Specifically, the parameters $\tilde{B}_{i}^{-}$and $\tilde{B}_{i}^{+}$on the right-hand side of constraints can be formulated as follows: $\left(u_{1}, v_{1}\right)$, $\left(u_{2}, v_{2}\right), \ldots,\left(u_{n}, v_{n}\right)$, where $u_{1}, u_{2}, \ldots, u_{n}$ and $v_{1}, v_{2}, \ldots, v_{n}$ are the random numbers of lower and upper bounds of $\tilde{B}_{i}^{ \pm}$ $\left(\tilde{B}_{i}^{-}\right.$and $\left.\tilde{B}_{i}^{+}\right)$. And $f(s, t)$ can be defined as the joint probability distribution function of $\left(\tilde{B}_{i}^{-}, \tilde{B}_{i}^{+}\right)$, where $s$ is the variable referring to $\tilde{B}_{i}^{-}$, and $t$ is the variable referring to $\tilde{B}_{i}^{+}$. Then, RBI can be incorporated into the interval fuzzy linear programming (IFLP) model through the introduction of membership grade $\lambda$ (Cao et al., 2010):

$\operatorname{Max} \lambda$

subject to

$C^{ \pm} X^{ \pm} \geq f^{+}+(1-\lambda)\left(f^{+}-f^{-}\right)$,

$A^{ \pm} X^{ \pm} \leq \tilde{B}^{-}+(1-\lambda)\left(\tilde{B}^{+}-\tilde{B}^{-}\right)$,

$X^{ \pm} \geq 0$

$0 \leq \lambda \leq 1$.

Let $\quad Z_{i}=\tilde{B}^{-}+(1-\lambda)\left(\tilde{B}^{+}-\tilde{B}^{-}\right)=\lambda \tilde{B}_{i}^{-}+(1-\lambda) \tilde{B}_{i}^{+}$. Given the joint probability distribution function of $\left(\tilde{B}_{i}^{-}, \tilde{B}_{i}^{+}\right)$is available, the distribution function of its linear combination $Z_{i}=\lambda \tilde{B}_{i}^{-}+(1-\lambda) \tilde{B}_{i}^{+}$can be calculated as follows:

$$
\begin{aligned}
& G_{i}(z, \lambda)=\operatorname{Pr}\left\{Z_{i} \leq z\right\}=\operatorname{Pr}\left\{\lambda \tilde{B}_{i}^{-}+(1-\lambda) \tilde{B}_{i}^{+} \leq z\right\} \\
& =\iint_{\lambda \tilde{B}_{i}^{-}+(1-\lambda) \tilde{B}_{i}^{+}} f(s, t) \mathrm{d} s \mathrm{~d} t .
\end{aligned}
$$

In this model, $\lambda$ represents not only the level of satisfying the objectives and constrains but also a linear combination parameter of the lower and upper bounds of RBI. Then RBI can be converted into a new random variable $\left[Z_{i}=\lambda \tilde{B}_{i}^{-}+(1-\lambda) \tilde{B}_{i}^{+}\right]$in IFLP, and the distribution function $\left[G_{i}(z, \lambda)\right]$ of $Z_{i}$ can be generated (Cao et al., 2010).

\subsection{Dual inexact fuzzy stochastic programming}

When a right-hand-side parameter is random, the CCP method should be adopted. Since parameters on the left-hand side are intervals, an interval chance-constrained linear programming (ICCP) can be developed (Huang et al., 1992,
1995). As $Z_{i}$ is a random variable with known distribution function, model (1) can be converted into the following (Cao et al., 2010; Cai et al., 2007, 2009a, b):

$\operatorname{Max} \lambda$

subject to

$C^{ \pm} X^{ \pm} \geq f^{+}+(1-\lambda)\left(f^{+}-f^{-}\right)$,

$\operatorname{Pr}\left\{A^{ \pm} X^{ \pm} \leq Z_{i}\right\} \geq 1-p_{i}, i=1,2, \ldots, m$,

$X^{ \pm} \geq 0$,

$0 \leq \lambda \leq 1$.

Model (2) can be converted into an "equivalent" deterministic version as follows:

$\operatorname{Max} \lambda$

subject to

$C^{ \pm} X^{ \pm} \geq f^{+}+(1-\lambda)\left(f^{+}-f^{-}\right)$,

$A_{i}^{ \pm} X^{ \pm} \leq Z_{i}^{\left(p_{i}\right)}, A_{i}^{ \pm} \in A^{ \pm}, i=1,2, \ldots, m$,

$X^{ \pm} \geq 0$,

$0 \leq \lambda \leq 1$,

where $Z_{i}^{\left(p_{i}\right)}=G_{i}^{-1}\left(p_{i}, \lambda\right)$. In CCP, the random variable on the right-hand side can be handled as several deterministic numbers corresponding to different violation probabilities $\left(p_{i}\right)$. However, $Z_{i}^{\left(p_{i}\right)}$ in this part is a function of $\lambda$ corresponding to $p_{i}$, because the distribution function of $Z_{i}\left[G_{i}^{-1}\left(p_{i}, \lambda\right)\right]$ is a function of $z$ and $\lambda$. When $p_{i}$ is a constant, then $G_{i}^{-1}\left(p_{i}, \lambda\right)$ is a function of $\lambda$ (Huang et al., 1992, 1995). Thus the solution method of the developed model will be different from the conventional CCP.

If $Z_{i}^{\left(p_{i}\right)}$ is a linear function of $\lambda$, according to solution algorithm developed by Huang et al. (1992, 1995), this model can be divided into two deterministic sub-models:

$\operatorname{Max} \lambda$

subject to

$\sum_{j=1}^{k} c_{j}^{+} x_{j}^{+}+\sum_{j=k+1}^{n} c_{j}^{+} x_{j}^{-} \geq f^{-}+(1-\lambda)\left(f^{+}-f^{-}\right)$,

$$
\begin{aligned}
& \sum_{j=1}^{k_{1}}\left|a_{i j}\right|^{-} \operatorname{sign}\left(a_{i j}^{-}\right) x_{j}^{+}+\sum_{j=k_{1}+1}^{n}\left|a_{i j}\right|^{+} \operatorname{sign}\left(a_{i j}^{+}\right) x_{j}^{-} \\
& \leq Z_{i}^{\left(p_{i}\right)}, i=1,2, \ldots, m, \\
& x_{j}^{+} \geq 0, j=1,2, \ldots, k \\
& x_{j}^{-} \geq 0, j=k+1, k+2, \ldots, n, \\
& 0 \leq \lambda \leq 1
\end{aligned}
$$


and

$\operatorname{Max} \lambda$

subject to

$\sum_{j=1}^{k} c_{j}^{-} x_{j}^{-}+\sum_{j=k+1}^{n} c_{j}^{-} x_{j}^{+} \geq f^{-}+(1-\lambda)\left(f^{+}-f^{-}\right)$,

$\sum_{j=1}^{k_{1}}\left|a_{i j}\right|^{+} \operatorname{sign}\left(a_{i j}^{+}\right) x_{j}^{-}+\sum_{j=k_{1}+1}^{n}\left|a_{i j}\right|^{-} \operatorname{sign}\left(a_{i j}^{-}\right) x_{j}^{+}$

$\leq Z_{i}^{\left(p_{i}\right)}, i=1,2, \ldots, m$,

$x_{j}^{ \pm} \geq 0, \forall j$,

$x_{j}^{-} \leq x_{j \text { opt }}^{+}, j=1,2, \ldots, k$,

$x_{j}^{+} \geq x_{j \mathrm{opt}}^{-}, \ldots j=k+1, k+2, \ldots, n$.

Among these two submodels, $f^{+}$and $f^{-}$correspond to the lower and upper bounds of the objective function values. When the objective function is to be minimized, sub-model corresponding to $f^{-}$is firstly formulated. And then the submodel corresponding to $f^{+}$can be obtained based on the solution of the first sub-model. Through solving these two submodels, the final interval solutions can be acquired as $\lambda$, $x_{j \mathrm{opt}}=\left[x_{j \mathrm{opt}}^{-}, x_{j \mathrm{opt}}^{+}\right]$, and $f_{\mathrm{opt}}=\left[f_{\mathrm{opt}}^{-}, f_{\mathrm{opt}}^{+}\right]$.

However, the two-step method encounters difficulties if $Z_{i}^{\left(p_{i}\right)}$ is not a linear function of $\lambda$. In this case, it should be converted to linear or stepwise linear functions of $\lambda$. The particular flow of this developed optimization method is displayed in Fig. 1.

\section{Application to water and farmland use management system with non-point source pollution mitigation}

\subsection{Overview of water and farmland use management system with non-point source pollution mitigation}

Increasing population, diminishing supplies and changing climatic conditions amplify difficulties in resolving the conflicts between human activities and environment. Since agriculture is one of the most important water users, the farmland use arrangement can directly or indirectly influence the water resources utilization and environment. Specifically, the abuse of fertilizer and pesticide can cause extensive anthropogenic non-point source pollution. Conversely, the water pollution control can also exert an impact on associated human activities, such as water allocation and cultivation. These all call for the need to integrate pollution mitigation efforts into the framework of water resources management. However, in real-world problems, various components in the water resource and agricultural land use management system impact each other, which inevitably leads to complexities and dynamics. For example, the interactions between population

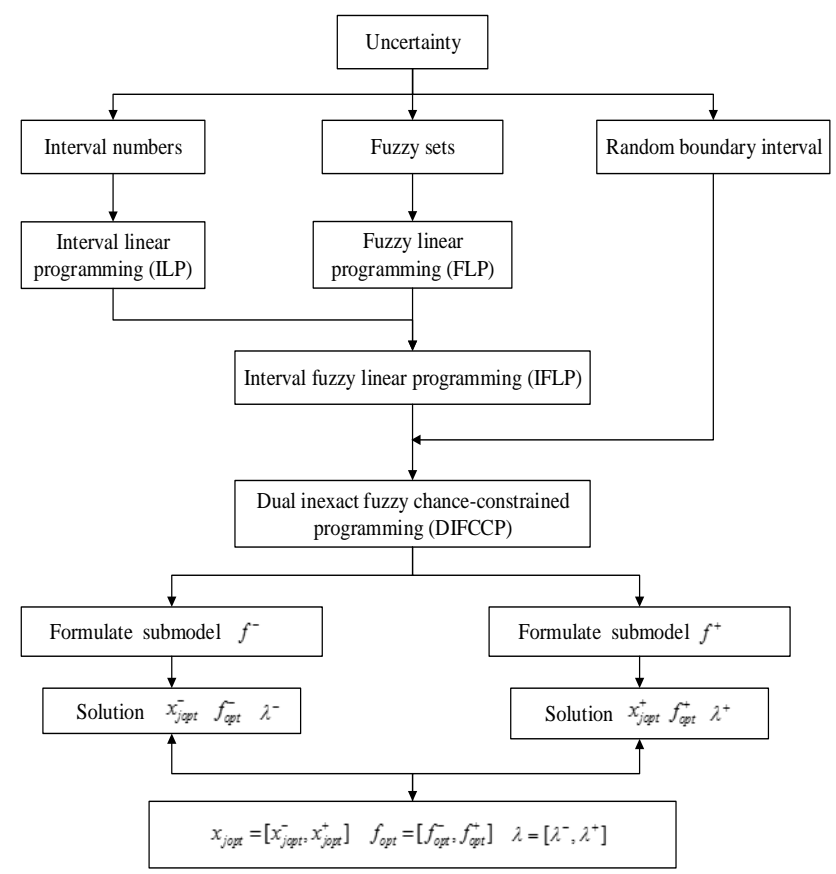

Fig. 1. Optimization method.

and water supplies can directly cause complex water utilization among various end users. This makes it critical to clarify the interactions among system factors and those intimately involved in the planning process (Chung et al., 2008).

Figure 2 presents a general water and farmland use management system, including internal and external factors. Specifically, resources availability, distribution, utilization technology, policy, security and other internal factors of water and agricultural land comprise the microscopic system, directly affecting the related planning processes. Besides, external factors such as social, economy, natural conditions, institutions, eco-environment (i.e., non-point source pollution), and population can exert indirect impacts on the entire system operation. Given the complexity of this system and the interactions among various components, uncertainty is a necessary consideration in the process of modeling. In addition, the uncertainties existing in this system can be also generated from the errors in data collection and parameter settings, subjective judgments of experts or stakeholders, as well as uncertainty due to the structure of adopted model (Lindenschmidt et al., 2007; Dong et al., 2013).

Therefore, several optimization technologies will be introduced to handle these uncertainties in this system. For example, economic coefficients (e.g., unit benefit of water supply and pollutants treatment cost), technological efficiencies, and continuous variables can be expressed as interval numbers. Given the random and dynamic features of water resources availabilities (i.e., surface drainage water, groundwater and river water), it is rather hard to accurately determine their two bounds. And the random boundary interval (RBI) will 


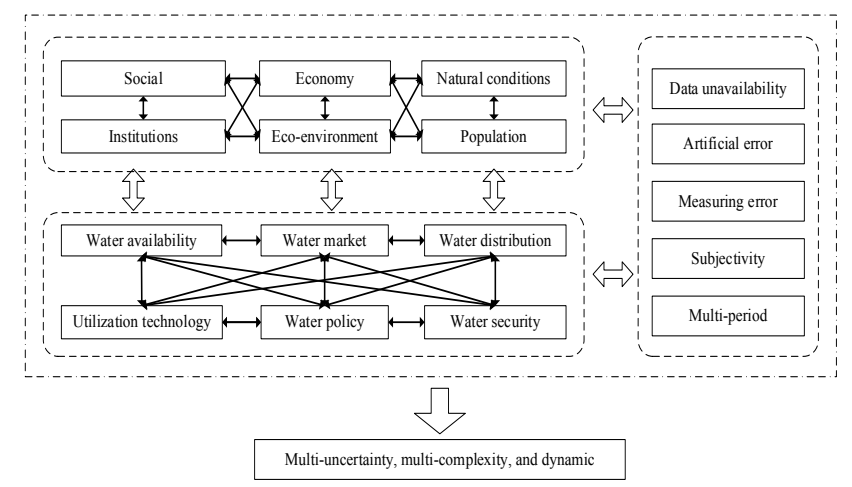

Fig. 2. Water and farmland use management system.

be adapted to reflect their dual uncertainty, with the lower and upper bounds of RBI being continuous random variables. Then, the developed dual-inexact fuzzy stochastic programming (DIFSP) method will be applied into a water and farmland use planning model (WFUPM) with non-point source pollution mitigation.

\subsection{Modeling formulation}

In the study case, three types of water resources (i.e., surface drainage water, groundwater, and river water) are major water supplies, meeting the regional water demands of various end users (i.e., agriculture, industry, tourism, residents, and municipal sector). Depending upon different intended uses for end users, surface water can be sent directly for industrial production and irrigation, or should be treated prior to drinking and other uses. Pumped groundwater can be delivered directly to all users before disinfection. River water can be provided to agricultural irrigation and industry production. Water is transferred between end users by pipes with limited capacities. In this study region, corn, potato, and rice are selected as the major crops, and metallurgical and food industries constitute local industry. Figure 3 gives an overview of the components and factors that need to be taken into account in this model (Dong et al., 2013). The study time horizon is 15 years and is further divided into three planning periods. With the consideration of these elements, water and farmland use planning model (WFUPM) with non-point source pollution mitigation can be formulated. Its objective is to maximize the total system benefit, covering benefit for agriculture irrigation, water supply benefits for industry, tourism, residents, and minus the costs for water pumping and delivering, as well as wastewater treatment, specifically as follows:

$$
\operatorname{Max} f^{ \pm}=f_{\mathrm{BC}}^{ \pm}+f_{\mathrm{BI}}^{ \pm}+f_{\mathrm{BT}}^{ \pm}+f_{\mathrm{BT}}^{ \pm}-f_{\mathrm{CW}}^{ \pm}-f_{\mathrm{CE}}^{ \pm}
$$

1. Benefit for agriculture irrigation

$f_{\mathrm{BC}}^{ \pm}=\sum_{i=1}^{3} \sum_{t=1}^{3}\left(\mathrm{PC}_{i t}^{ \pm} \cdot Y_{i t}^{ \pm}-\mathrm{CC}_{i t}^{ \pm}\right) A_{i t}^{ \pm}$

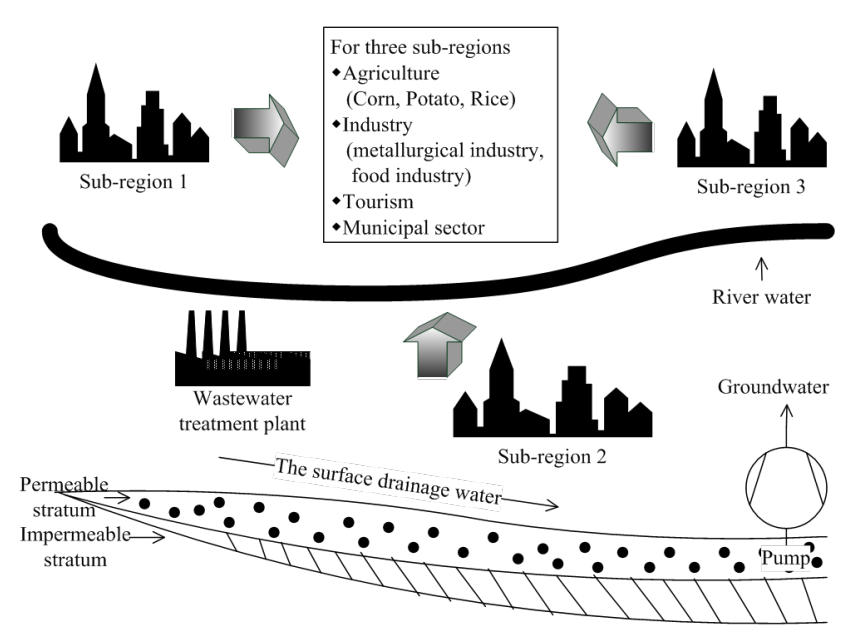

Fig. 3. The typical regional farmland use and water resources system.

2. Water supply benefit for industry

$f_{\mathrm{BI}}^{ \pm}=\sum_{k=1}^{2} \sum_{t=1}^{3} \mathrm{QI}_{k t}^{ \pm} \cdot \mathrm{ZI}_{k t}^{ \pm}$

3. Water supply benefit for tourism

$f_{\mathrm{BT}}^{ \pm}=\sum_{t=1}^{3} \mathrm{QT}_{t}^{ \pm} \cdot \mathrm{ZT}_{t}^{ \pm}$

4. Water supply benefit for residents

$f_{\mathrm{BT}}^{ \pm}=\sum_{t=1}^{3} \mathrm{QR}_{t}^{ \pm} \cdot \mathrm{ZR}_{t}^{ \pm}$

5. Cost of water pumping and delivering

$f_{\mathrm{CW}}^{ \pm}=\sum_{t=1}^{3}\left(\mathrm{QS}_{t}^{ \pm} \cdot \mathrm{WS}_{t}^{ \pm}+\mathrm{QG}_{t}^{ \pm} \cdot \mathrm{WG}_{t}^{ \pm}+\mathrm{QR}_{t}^{ \pm} \cdot \mathrm{WR}_{t}^{ \pm}\right)$

6. Cost of wastewater treatment

$$
\begin{aligned}
f_{\mathrm{CE}}^{ \pm} & =\sum_{t=1}^{3}\left(\mathrm{QWT}_{t}^{ \pm} \cdot \mathrm{DWT}_{t}^{ \pm} \cdot \mathrm{ZT}_{t}^{ \pm}+\mathrm{QWM}_{t}^{ \pm} \cdot \mathrm{DWM}_{t}^{ \pm}\right. \\
& \left.\cdot \mathrm{ZM}_{t}^{ \pm}+\mathrm{QWR}_{t}^{ \pm} \cdot \mathrm{DWM}_{t}^{ \pm} \cdot \mathrm{ZR}_{t}^{ \pm}\right) \\
& +\sum_{k=1}^{2} \sum_{t=1}^{3}\left(\mathrm{QWI}_{k t}^{ \pm} \cdot \mathrm{DWI}_{k t}^{ \pm} \cdot \mathrm{ZI}_{k t}^{ \pm}\right)
\end{aligned}
$$

Constraints:

1. Balance for farmland use

$\mathrm{MINA}_{t} \leq \sum_{i=1}^{3} A_{i t}^{ \pm} \leq \mathrm{MAXA}_{t}, \forall t$ 
2. Balance for water resource availability

$\mathrm{WS}_{t}^{ \pm} \leq \mathrm{MS}_{t}^{ \pm}, \forall t$
$\mathrm{WG}_{t}^{ \pm} \leq \mathrm{MG}_{t}^{ \pm}, \forall t$
$\mathrm{WR}_{t}^{ \pm} \leq \mathrm{MR}_{t}^{ \pm}, \forall t$

$\sum_{i=1}^{2} \mathrm{RWC}_{i t}^{ \pm} \cdot A_{i t}^{ \pm}+\sum_{k=1}^{2} \mathrm{ZI}_{k t}^{ \pm}+\mathrm{ZT}_{t}^{ \pm}+\mathrm{ZM}_{t}^{ \pm}+\mathrm{ZR}_{t}^{ \pm}$

$+\mathrm{RWG}_{t}^{ \pm} \cdot \mathrm{GA}_{t}^{ \pm} \leq \mathrm{WS}_{t}^{ \pm}+\mathrm{WG}_{t}^{ \pm}+\mathrm{WR}_{t}^{ \pm}, \forall t$

3. Balance for water supply

$\sum_{i=1}^{2} \mathrm{RWC}_{i t}^{ \pm} \cdot A_{i t}^{ \pm} \geq \mathrm{MA}_{t}^{ \pm}, \forall t$

$\sum_{k=1}^{2} \mathrm{ZI}_{k t}^{ \pm} \geq \mathrm{MI}_{t}^{ \pm}, \forall t$

$\mathrm{ZT}_{t}^{ \pm} \geq \mathrm{MT}_{t}^{ \pm}, \forall t$

$\mathrm{ZM}_{t}^{ \pm} \geq \mathrm{MM}_{t}^{ \pm}, \forall t$

$\mathrm{ZR}_{t}^{ \pm} \geq \mathrm{MR}_{t}^{ \pm}, \forall t$

4. Balance for wastewater treatment

$\mathrm{DWI}_{k t}^{ \pm} \cdot \mathrm{ZI}_{k t}^{ \pm}+\mathrm{DWT}_{t}^{ \pm} \cdot \mathrm{ZT}_{t}^{ \pm}+\mathrm{DWM}_{t}^{ \pm} \cdot \mathrm{ZM}_{t}^{ \pm}$

$+\mathrm{DWR}_{t}^{ \pm} \cdot \mathrm{ZR}_{t}^{ \pm} \leq \mathrm{TWC}_{t}, \forall t$

5. Non-point pollution control constraints

$$
\begin{aligned}
& \sum_{i=1}^{3} \mathrm{NA}_{t}^{ \pm} \cdot A_{i t}^{ \pm}+ \\
& \left(\sum_{k=1}^{2} \mathrm{NI}_{k t}^{ \pm} \cdot \mathrm{ZI}_{k t}^{ \pm}+\mathrm{NT}_{t}^{ \pm} \cdot \mathrm{ZT}_{t}^{ \pm}+\mathrm{NM}_{t}^{ \pm} \cdot \mathrm{ZM}_{t}^{ \pm}+\mathrm{NR}_{t}^{ \pm} \cdot \mathrm{ZR}_{t}^{ \pm}\right) \\
& \left(1-\mathrm{NRE}_{t}^{ \pm}\right) \leq \mathrm{TN}_{t}^{ \pm}, \forall t
\end{aligned}
$$

$$
\begin{aligned}
& \sum_{i=1}^{3} \mathrm{PA}_{t}^{ \pm} \cdot A_{i t}^{ \pm}+ \\
& \left(\sum_{k=1}^{2} \mathrm{PI}_{k t}^{ \pm} \cdot \mathrm{ZI}_{k t}^{ \pm}+\mathrm{PT}_{t}^{ \pm} \cdot \mathrm{ZT}_{t}^{ \pm}+\mathrm{PM}_{t}^{ \pm} \cdot \mathrm{ZM}_{t}^{ \pm}+\mathrm{PR}_{t}^{ \pm} \cdot \mathrm{ZR}_{t}^{ \pm}\right) \\
& \left(1-\mathrm{PRE}_{t}^{ \pm}\right) \leq \mathrm{TP}_{t}^{ \pm}, \forall t
\end{aligned}
$$

where $f=$ expected net system benefit (USD); $t=$ time period, $t=1,2,3 ; i=$ type of crop, $i=1,2,3$ (where $i=1$ for corn, 2 for potato, 3 for rice); $k=$ type of industry, $k=1$, 2 (where $k=1$ for metallurgical industry, 2 for food industry); $\mathrm{PC}_{i t}^{ \pm}=$price of crop $i$ in period $t\left(\mathrm{USD} \mathrm{kg}^{-1}\right) ; \mathrm{Y}_{i t}^{ \pm}=$ yield of crop $i$ in period $t\left(\mathrm{~kg} \mathrm{~km}^{-2}\right)$; $\mathrm{CC}_{i t}^{ \pm}=$cost of cultivating crop $i$ in period $t\left(\mathrm{USD} \mathrm{km}^{-2}\right)$; $\mathrm{QI}_{k t}^{ \pm}=$unit benefit of water allocated to industry $k$ in period $t\left(\mathrm{USD} \mathrm{m}^{-3}\right)$;
$\mathrm{QT}_{t}^{ \pm}=$unit benefit of water allocated to tourism in period $t\left(\mathrm{USD} \mathrm{m}^{-3}\right) ; \mathrm{QR}_{t}^{ \pm}=$unit benefit of water allocated to household in period $t\left(\mathrm{USD} \mathrm{m}^{-3}\right)$; $\mathrm{QG}_{t}^{ \pm}=$cost of cultivating green field in period $t\left(\mathrm{USD} \mathrm{km}^{-2}\right)$; $\mathrm{QS}_{t}^{ \pm}=$cost of pumping and delivering the surface drainage water in period $t\left(\mathrm{USD} \mathrm{m}^{-3}\right) ; \mathrm{QG}_{t}^{ \pm}=$cost of pumping and delivering the groundwater in period $t\left(\mathrm{USD} \mathrm{m}^{-3}\right) ; \mathrm{QR}_{t}^{ \pm}=$cost of pumping and delivering the river water in period $t\left(\mathrm{USD} \mathrm{m}^{-3}\right)$; $\mathrm{QWI}_{k t}^{ \pm}=$treatment cost of wastewater from industry $k$ in period $t\left(\mathrm{USD} \mathrm{t}^{-1}\right)$; $\mathrm{QWT}_{t}^{ \pm}=$treatment cost of wastewater from tourism in period $t\left(\mathrm{USD}^{-1}\right) ; \mathrm{QWM}_{t}^{ \pm}=$treatment cost of wastewater from municipal sector in period $t\left(\mathrm{USD} \mathrm{t}^{-1}\right)$; $\mathrm{QWR}_{t}^{ \pm}=$treatment cost of wastewater from household in period $t\left(\mathrm{USD} \mathrm{t}^{-1}\right)$; $\mathrm{DWI}_{k t}^{ \pm}=$unit wastewater discharge by industry $k$ in period $t\left(\mathrm{t} \mathrm{m}^{-3}\right)$; $\mathrm{DWT}_{t}^{ \pm}=$unit wastewater discharge by tourism industry in period $t\left(\mathrm{t} \mathrm{m}^{-3}\right)$; $\mathrm{DWM}_{t}^{ \pm}=$unit wastewater discharge by municipal sector in period $t\left(\mathrm{tm}^{-3}\right)$; $\mathrm{DWR}_{t}^{ \pm}=$unit wastewater discharge by household in period $t\left(\mathrm{t} \mathrm{m}^{-3}\right)$; MAXA $t=$ the maximum area allocated to crop $i$ in period $t\left(\mathrm{~km}^{2}\right) ; \mathrm{MINA}_{t}=$ the minimum area allocated to crop $i$ in period $t\left(\mathrm{~km}^{2}\right) ; \mathrm{MS}_{t}^{ \pm}=$the maximum allocated amount of surface drainage water in period $t$ $\left(\mathrm{m}^{3}\right) ; \mathrm{MG}_{t}^{ \pm}=$the maximum allocated amount of groundwater in period $t\left(\mathrm{~m}^{3}\right) ; \mathrm{MR}_{t}^{ \pm}=$the maximum allocated amount of river water in period $t\left(\mathrm{~m}^{3}\right)$; $\mathrm{RWC}_{i t}^{ \pm}=$unit irrigation demand for crop $i$ in period $t\left(\mathrm{~m}^{3} \mathrm{~km}^{-2}\right)$; $\mathrm{RWG}_{t}^{ \pm}=$unit irrigation demand for green field in period $t\left(\mathrm{~m}^{3} \mathrm{~km}^{-2}\right)$; $\mathrm{MA}_{t}^{ \pm}=$ water demand of agriculture in period $t\left(\mathrm{~m}^{3}\right) ; \mathrm{MI}_{t}^{ \pm}=$water demand of industry in period $t\left(\mathrm{~m}^{3}\right)$; $\mathrm{MT}_{t}^{ \pm}=$water demand of tourism in period $t\left(\mathrm{~m}^{3}\right) ; \mathrm{MM}_{t}^{ \pm}=$water demand of municipal sector in period $t\left(\mathrm{~m}^{3}\right) ; \mathrm{MR}_{t}^{ \pm}=$water demand of household in period $t\left(\mathrm{~m}^{3}\right)$; $\mathrm{TWC}_{t}=$ total wastewater treatment capacity in period $t(\mathrm{t}) ; \mathrm{NA}_{t}^{ \pm}=$nitrogen percent content of the soil in period $t(\%) ; \mathrm{PA}_{t}^{ \pm}=$phosphorus percent content of the soil in period $t(\%)$; $\mathrm{NI}_{k t}^{ \pm}=$unit nitrogen discharge by industry $k$ in period $t\left(\mathrm{t} \mathrm{m}^{-3}\right)$; $\mathrm{PI}_{k t}^{ \pm}=$unit phosphor discharge by industry $k$ in period $t\left(\mathrm{t} \mathrm{m}^{-3}\right) ; \mathrm{NT}_{t}^{ \pm}=$unit nitrogen discharge by tourism in period $t\left(\mathrm{t} \mathrm{m}^{-3}\right)$; $\mathrm{PT}_{t}^{ \pm}=$unit phosphor discharge by tourism in period $t\left(\mathrm{t} \mathrm{m}^{-3}\right) ; \mathrm{NM}_{t}^{ \pm}=$unit nitrogen discharge by municipal sector in period $t\left(\mathrm{t} \mathrm{m}^{-3}\right)$; $\mathrm{PM}_{t}^{ \pm}=$unit phosphor discharge by municipal sector in period $t\left(\mathrm{tm}^{-3}\right) ; \mathrm{NR}_{t}^{ \pm}=$unit nitrogen discharge by household in period $t\left(\mathrm{t} \mathrm{m}^{-3}\right) ; \mathrm{PR}_{t}^{ \pm}=$unit phosphor discharge by household in period $t\left(\mathrm{t} \mathrm{m}^{-3}\right)$; $\mathrm{NRE}_{t}^{ \pm}=$nitrogen removal efficiency in period $t(\%)$; $\mathrm{PRE}_{t}^{ \pm}=$phosphor removal efficiency in period $t(\%) ; \mathrm{TN}_{t}^{ \pm}=$the maximum allowed amount of nitrogen discharge in period $t(\mathrm{~kg}) ; \mathrm{TP}_{t}^{ \pm}=$the maximum allowed amount of phosphor discharge in period $t(\mathrm{~kg})$; $A_{i t}^{ \pm}=$area allocated to crop $i$ in period $t\left(\mathrm{~km}^{2}\right) ; \mathrm{ZI}_{k t}^{ \pm}=$water allocated to industry $k$ in period $t\left(\mathrm{~m}^{3}\right) ; \mathrm{ZT}_{t}^{ \pm}=$water allocated to tourism in period $t\left(\mathrm{~m}^{3}\right) ; \mathrm{ZM}_{t}^{ \pm}=$water allocated to municipal sector in period $t\left(\mathrm{~m}^{3}\right) ; \mathrm{ZR}_{t}^{ \pm}=$water allocated to household in period $t\left(\mathrm{~m}^{3}\right)$; $\mathrm{WS}_{t}^{ \pm}=$allocated amount of surface drainage water in period $t\left(\mathrm{~m}^{3}\right) ; \mathrm{WG}_{t}^{ \pm}=$allocated 
Table 1. Benefits of water supply for end users (USD m ${ }^{-3}$ ).

\begin{tabular}{lrrr}
\hline \multirow{2}{*}{ End user } & \multicolumn{3}{c}{ Period } \\
\cline { 2 - 4 } & $t=1$ & $t=2$ & $t=3$ \\
\hline Metallurgical industry & {$[27.57,29.56]$} & {$[25.53,27.31]$} & {$[23.77,24.67]$} \\
Food industry & {$[14.86,15.09]$} & {$[14.29,14.45]$} & {$[13.64,13.77]$} \\
Tourism & {$[9.11,9.25]$} & {$[8.76,8.86]$} & {$[8.36,8.44]$} \\
Household & {$[14.26,25.3]$} & {$[31.95,43.42]$} & {$[44.77,45.48]$} \\
\hline
\end{tabular}

Data source: Dong et al. (2013, 2014).

Table 2. Costs for pumping and delivering water resources (USDm ${ }^{-3}$ ).

\begin{tabular}{|c|c|c|c|}
\hline \multirow{2}{*}{ Water resource type } & \multicolumn{3}{|c|}{ Period } \\
\hline & $t=1$ & $t=2$ & $t=3$ \\
\hline Surface drainage water groundwater & {$[0.0033,0.0034]$} & {$[0.0032,0.0033]$} & {$[0.0031,0.0032]$} \\
\hline Groundwater & {$[0.0056,0.0062]$} & {$[0.0054,0.0059]$} & {$[0.0052,0.0057]$} \\
\hline River water & {$[0.0062,0.0063]$} & {$[0.0060,0.0061]$} & {$[0.0058,0.0059]$} \\
\hline
\end{tabular}

Data source: Dong et al. (2013, 2014).

amount of groundwater in period $t\left(\mathrm{~m}^{3}\right) ; \mathrm{WR}_{t}^{ \pm}=$allocated amount of river water in period $t\left(\mathrm{~m}^{3}\right)$.

In order to generate optimal system solutions, several effective constraints are formulated to restrain the entire model for the purpose of maximizing system benefit. Particularly, farmland use, including the planting areas of corn, potato, and rice, should be limited to available farmland resources. All kinds of water resources have their own availabilities every period due to the natural and policy limitations. Water supplies to each end user should satisfy their operational demands. The wastewater discharged to the central treatment plant should not excess its fixed capacity. Finally, the total quantity control should be applied to control the discharge amount of non-point source pollution (i.e., nitrogen and phosphorus). The benefits of water supply for end users and costs for pumping and delivering water resources are displayed in Tables 1 and 2. In this model, the RBIs are combined with the water resources availabilities, and Table 3 presents the linearization results of surface water availability.

\section{Analysis of results}

Through computing a developed water and farmland use planning model (WFUPM) with non-point source pollution mitigation, a series of related schemes were generated. Particularly, they can provide useful plans of planting areas for crops, water allocations to each end user, water resources supplies, and non-point source pollution control under various water supply conditions and system reliabilities. In addition, the solutions obtained from ICCP and DIFSP were compared to demonstrate the efficiency of new developed optimization method for tackling uncertainties in water and farmland use system.
According to the climate of northern China, corn, potato, and rice are chosen as the staple crops. The crop planting areas under $p_{i}=0.01$ are presented in Table 4. Obviously, potato would be the major crop in this region, encompassing planting areas of [138.31, 146.85], [131.98, 140.62], and $[125.66,132.61] \mathrm{km}^{2}$ in periods 1 to 3 , respectively. Then corn would occupy the second position of crop planning, which would require [7.65, 9.9], [7.3, 9.48], and [6.95, $8.94] \mathrm{km}^{2}$ in these three periods. Finally, [7.04, 8.25], [6.72, $7.9]$, and $[6.39,7.45] \mathrm{km}^{2}$ of areas would be used to plant rice in periods 1 to 3 , respectively. Mainly due to imported vegetables and food, the planting areas of these crops decrease each period.

Table 5 shows the solutions of water allocations to various end users under $p_{i}=0.01$, mainly including agriculture, metallurgical industry, food industry, tourism, residents, and municipal sector. Among them, residents are still the biggest consumer, utilizing [32.61, 33.69], [31.34, 32.27], and $[29.93,30.76]$ million $\mathrm{m}^{3}$ in periods 1,2 , and 3 , respectively. For providing vegetables and rice to local residents, [27.57, 29.56], [25.53, 27.31], and [23.77, 24.67] million $\mathrm{m}^{3}$ of water would be allocated to agricultural production in these three periods. Municipal sector is another important water user, which would require [16.78, 19.47], [16.13, 18.64], and [15.41, 17.77] million $\mathrm{m}^{3}$. Furthermore, local industries also need adequate water to ensure their normal operations, such as metallurgical industry consuming [14.86, 15.09], [14.29, 14.45], and [13.64, 13.77] million $\mathrm{m}^{3}$ of water resources in periods 1 to 3 , respectively. As the tourism develops, it would consume a rather large proportion of water usage, increasing from $[14.26,25.3]$ million $\mathrm{m}^{3}$ in period 1 , through $[31.95,43.42]$ million $\mathrm{m}^{3}$ in period 2 , to $[44.77$, 
Table 3. Linearization results of surface water availability.

\begin{tabular}{lllll}
\hline \multirow{2}{*}{ Period } & $p_{i}$ value & $G_{i}^{-1} p_{i}, \lambda / Z_{i}^{p_{i}}$ & $\lambda=[0,0.10]$ & $\lambda=[0.81,0.90]$ \\
\hline & $p_{i}=0.01$ & $-2.23 \sqrt{0.34 \lambda^{2}-0.51 \lambda+0.56}+27.85-1.43 \lambda$ & $-0.0068 \lambda+26.107$ & $-0.0157 \lambda+25.291$ \\
\multirow{3}{*}{$t=1$} & $p_{i}=0.05$ & $-1.64 \sqrt{0.34 \lambda^{2}-0.51 \lambda+0.56}+27.85-1.43 \lambda$ & $-0.0090 \lambda+26.623$ & $-0.0153 \lambda+25.710$ \\
& $p_{i}=0.10$ & $-1.28 \sqrt{0.34 \lambda^{2}-0.51 \lambda+0.56}+27.85-1.43 \lambda$ & $-0.0102 \lambda+26.893$ & $-0.0150 \lambda+25.929$ \\
& $p_{i}=0.15$ & $-1.03 \sqrt{0.34 \lambda^{2}-0.51 \lambda+0.56}+27.85-1.43 \lambda$ & $-0.0110 \lambda+27.080$ & $-0.0149 \lambda+26.080$ \\
\hline & $p_{i}=0.01$ & $-2.23 \sqrt{0.27 \lambda^{2}-0.67 \lambda+0.94}+26.91-1.76 \lambda$ & $-0.0098 \lambda+24.651$ & $-0.0152 \lambda+23.590$ \\
\multirow{2}{*}{$t=2$} & $p_{i}=0.05$ & $-1.64 \sqrt{0.27 \lambda^{2}-0.67 \lambda+0.94}+26.91-1.76 \lambda$ & $-0.0121 \lambda+25.320$ & $-0.0153 \lambda+24.257$ \\
& $p_{i}=0.10$ & $-1.28 \sqrt{0.27 \lambda^{2}-0.67 \lambda+0.94}+26.91-1.76 \lambda$ & $-0.0133 \lambda+25.669$ & $-0.0158 \lambda+24.530$ \\
& $p_{i}=0.15$ & $-1.03 \sqrt{0.27 \lambda^{2}-0.67 \lambda+0.94}+26.91-1.76 \lambda$ & $-0.0141 \lambda+25.912$ & $-0.0162 \lambda+24.720$ \\
\hline & $p_{i}=0.01$ & $-2.23 \sqrt{0.14 \lambda^{2}-0.22 \lambda+0.72}+26.32-1.33 \lambda$ & $-0.0105 \lambda+24.343$ & $-0.0136 \lambda+23.402$ \\
\multirow{2}{*}{$t=3$} & $p_{i}=0.05$ & $-1.64 \sqrt{0.14 \lambda^{2}-0.22 \lambda+0.72}+26.32-1.33 \lambda$ & $-0.0113 \lambda+24.929$ & $-0.0135 \lambda+23.951$ \\
& $p_{i}=0.10$ & $-1.28 \sqrt{0.14 \lambda^{2}-0.22 \lambda+0.72}+26.32-1.33 \lambda$ & $-0.0117 \lambda+25.234$ & $-0.0135 \lambda+24.237$ \\
& $p_{i}=0.15$ & $-1.03 \sqrt{0.14 \lambda^{2}-0.22 \lambda+0.72}+26.32-1.33 \lambda$ & $-0.0120 \lambda+25.446$ & $-0.0134 \lambda+24.436$ \\
\hline
\end{tabular}

Table 4. Crop planting $\left(\mathrm{km}^{2}\right)$.

\begin{tabular}{lrrr}
\hline \multirow{3}{*}{ End user } & \multicolumn{3}{c}{ Period } \\
\cline { 2 - 4 } & $t=1$ & $t=2$ & $t=3$ \\
\hline Corn & {$[7.65,9.9]$} & {$[7.3,9.48]$} & {$[6.95,8.94]$} \\
Potato & {$[138.31,146.85]$} & {$[131.98,140.62]$} & {$[125.66,132.61]$} \\
Rice & {$[7.04,8.25]$} & {$[6.72,7.9]$} & {$[6.39,7.45]$} \\
\hline
\end{tabular}

Table 5. Water allocations to end users (million $\mathrm{m}^{3}$ ).

\begin{tabular}{lrrr}
\hline \multirow{2}{*}{ End user } & \multicolumn{3}{c}{ Period } \\
\cline { 2 - 4 } & $t=1$ & $t=2$ & $t=3$ \\
\hline Agriculture & {$[27.57,29.56]$} & {$[25.53,27.31]$} & {$[23.77,24.67]$} \\
Metallurgical industry & {$[14.86,15.09]$} & {$[14.29,14.45]$} & {$[13.64,13.77]$} \\
Food industry & {$[9.11,9.25]$} & {$[8.76,8.86]$} & {$[8.36,8.44]$} \\
Tourism & {$[14.26,25.3]$} & {$[31.95,43.42]$} & {$[44.77,45.48]$} \\
Residents & {$[32.61,33.69]$} & {$[31.34,32.27]$} & {$[29.93,30.76]$} \\
Municipal sector & {$[16.78,19.47]$} & {$[16.13,18.64]$} & {$[15.41,17.77]$} \\
\hline
\end{tabular}

45.48] million $\mathrm{m}^{3}$ in period 3 , which should arouse the general concern of relevant department.

Table 6 presents the solutions of water pollution control. In this study, the model mainly considers wastewater and nonpoint source pollution (i.e., total nitrogen and phosphorus). Restrained by the capacities of pollution treatment, [28.12, 29.75], [30.64, 31.29], and [28.22, 31.15] $\times 10^{3} \mathrm{t}$ of wastewater would be allowed to discharge to the sewage treatment facilities in periods 1,2 , and 3. For total nitrogen, [1.27, $1.34],[1.18,1.24]$, and $[0.98,1] \times 10^{3} \mathrm{t}$ would be the nitrogen allowances in these three periods. In addition, [0.49, $0.50],[0.44,0.45]$, and $[0.34,0.36] \times 10^{3} \mathrm{t}$ of total phosphorus could be disposed to local treatment system. In order to protect the water environment, the discharge quantities of
Table 6. Water pollution control $\left(10^{3} \mathrm{t}\right)$.

\begin{tabular}{lrrr}
\hline \multirow{3}{*}{ End user } & \multicolumn{3}{c}{ Period } \\
\cline { 2 - 4 } & $t=1$ & $t=2$ & $t=3$ \\
Wastewater & {$[28.12,29.75]$} & {$[30.64,31.29]$} & {$[28.22,31.15]$} \\
Total nitrogen & {$[1.27,1.34]$} & {$[1.18,1.24]$} & {$[0.98,1]$} \\
Total phosphorus & {$[0.49,0.50]$} & {$[0.44,0.45]$} & {$[0.34,0.36]$} \\
\hline
\end{tabular}

water pollutants should be controlled within local capacities according to current technological development situation.

In this research, four $p_{i}$ values are defined, including 0.01 , $0.05,0.10$, and 0.15 . Generally, a higher $p_{i}$ value indicates a higher probability of constraint violation, resulting in a larger volume of water supplies and a higher system benefit. As shown in Table 7, the quantity from surface drainage water in period 1 would be [20.73, 21.54], [21.07, 21.96], $[21.25,22.18]$, and $[21.37,22.24]$ million $\mathrm{m}^{3}$ under a $p_{i}$ level of $0.01,0.05,0.10$, and 0.15 , respectively. The corresponding volume of groundwater would be [28.33, 29.14], [28.69, 29.62], [28.87, 29.88], and [29, 30.05] million $\mathrm{m}^{3}$. Similarly, when the $p_{i}$ value changes from 0.01 to 0.15 , the amount of river water would increase from $[102.79,107.79]$ to [104.61, 109.38] million $\mathrm{m}^{3}$. From periods 1 to 3 , a downward trend would be observed for the amounts of water supplied. For example, under a $p_{i}$ level of 0.01 , the amount of groundwater would be [28.33, 29.14], [26.52, 27.61], and [21.91, 24.16] million $\mathrm{m}^{3}$ in periods 1 to 3 , respectively. Such a decrease is probably contributed by the advancement of water-saving techniques and the improved efficiency in water utilization.

Since $p_{i}$ value represents the probability of the constraint being violated, higher $p_{i}$ values mean higher probability of constraint violations, presenting higher system failure risks and leading to a decreased reliability in fulfilling the system 
Table 7. Water resources supplies under different $p_{i}$ values $\left(\right.$ million $\mathrm{m}^{3}$ ).

\begin{tabular}{lrrrrr}
\hline \multirow{2}{*}{ Water resource type } & \multirow{2}{*}{ Period } & \multicolumn{4}{c}{$p_{i}$ value } \\
\cline { 3 - 6 } & & $p_{i}=0.01$ & $p_{i}=0.05$ & $p_{i}=0.10$ & $p_{i}=0.15$ \\
\hline \multirow{3}{*}{ Surface drainage water } & $t=1$ & {$[20.73,21.54]$} & {$[21.96,21.07]$} & {$[22.18,21.25]$} & {$[22.24,21.37]$} \\
& $t=2$ & {$[19.45,20.34]$} & {$[20.89,19.88]$} & {$[21.17,20.1]$} & {$[21.25,20.26]$} \\
& $t=3$ & {$[19.18,20.08]$} & {$[20.57,19.63]$} & {$[20.81,19.86]$} & {$[20.88,20.03]$} \\
\hline \multirow{3}{*}{ Groundwater } & $t=1$ & {$[28.33,29.14]$} & {$[29.62,28.69]$} & {$[29.88,28.87]$} & {$[30.05,29]$} \\
& $t=2$ & {$[26.52,27.61]$} & {$[27.97,26.77]$} & {$[28.16,26.91]$} & {$[28.29,27]$} \\
& $t=3$ & {$[21.91,24.16]$} & {$[24.94,22.71]$} & {$[25.34,23.13]$} & {$[25.62,23.42]$} \\
\hline \multirow{3}{*}{ River water } & $t=1$ & {$[102.79,107.79]$} & {$[108.63,103.75]$} & {$[109.07,104.26]$} & {$[109.38,104.61]$} \\
& $t=2$ & {$[98.26,103.88]$} & {$[105.24,99.14]$} & {$[105.95,99.6]$} & {$[106.44,99.92]$} \\
& $t=3$ & {$[96.37,102.06]$} & {$[103.2,97.15]$} & {$[103.79,97.56]$} & {$[104.2,97.84]$} \\
\hline
\end{tabular}

Table 8. System benefit from ICCP and DIFSP (USD million).

\begin{tabular}{lrrrr}
\hline \multirow{2}{*}{ Optimization method } & \multicolumn{4}{c}{$p_{i}$ value } \\
\cline { 2 - 5 } & $p_{i}=0.01$ & $p_{i}=0.05$ & $p_{i}=0.10$ & $p_{i}=0.15$ \\
\hline ICCP & {$[314.95,370.04]$} & {$[314.97,371.82]$} & {$[314.95,372.76]$} & {$[314.94,373.40]$} \\
DIFSP & {$[316.02,367.71]$} & {$[317.54,370.16]$} & {$[317.71,371.09]$} & {$[317.70,371.74]$} \\
\hline
\end{tabular}

requirements, but generating higher benefits. Conversely, lower $p_{i}$ values correspond to lower system risks and lower benefits. Figure 4 shows the effects of varied $p_{i}$ values on the system benefit under upper bound. Specifically, the system benefits would increase from USD [316.02, 367.71], [317.54, 370.16], and [317.71, 371.09], to [317.70, 371.74] million USD under $p_{i}=0.01,0.05,0.10$, and 0.15 , respectively.

Moreover, the satisfaction degree $\lambda^{ \pm}$presents the flexibility in the constraints and fuzziness in the objective, which indicates the decision makers' preferences regarding the tradeoffs between environment and economy, as well as system reliability and benefit. Generally, higher $\lambda^{ \pm}$level means decreased system reliability, with a higher benefit, being consistent with higher $p_{i}$ value; in comparison, lower $\lambda^{ \pm}$level presents decreased system reliability with a lower system benefit, corresponding to a lower $p_{i}$ value. Figure 5 represents the satisfaction degrees under different $p_{i}$ values under upper bound. Particularly, the satisfaction degrees would increase with $p_{i}$ values, rising from [0.017, 0.829], [0.041, $0.868]$, and $[0.043,0.882]$, to $[0.043,0.892]$ under $p_{i}=0.01$, $0.05,0.10$, and 0.15 , respectively.

In order to further demonstrate that the method DIFSP is more applicable than ICCP in dealing with water resources and farmland use management problems under uncertainty, a comparable study was conducted between the generated solutions from these two optimization methods. Letting the lower and upper bounds of RBIs equal their mid-values, the model would be simplified into a conventional inexact chance-constrained programming (ICCP) problem (Cao et al., 2010). The system benefits obtained through ICCP and

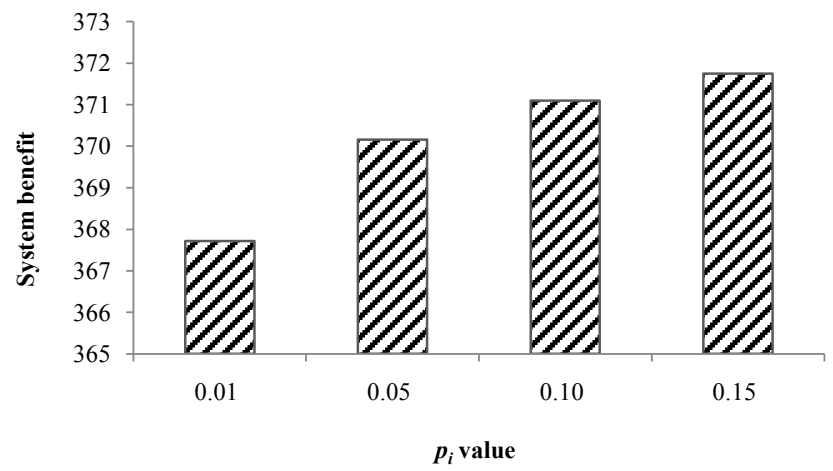

Fig. 4. System benefit under different $p_{i}$ values (upper bound).

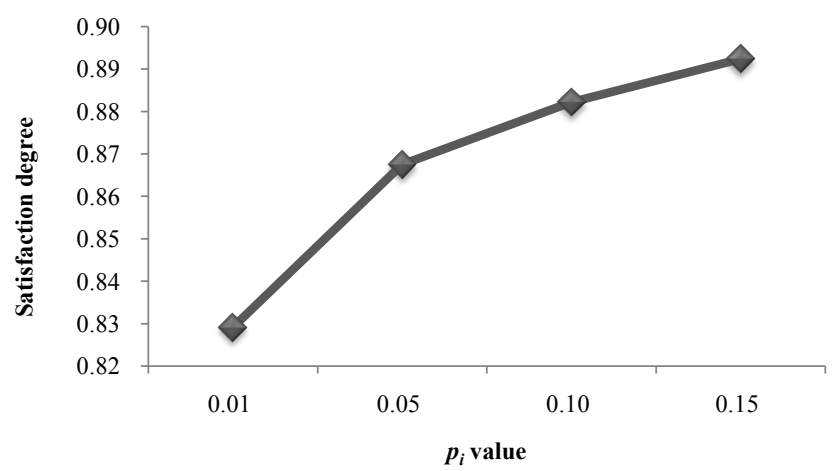

Fig. 5. Satisfaction degrees under different $p_{i}$ values (upper bound). 
DIFSP are presented in Table 8, which indicates that the results of DIFSP are much more robust than those of ICCP, meaning that the solution width of DIFSP is tighter and less uncertain. For instance, the system benefits computed from ICCP and DIFSP would be [314.95, 370.04] and [316.02, 367.71] million USD under $p_{i}=0.01$, obviously becoming tightened. This comparison convincingly certifies the effectiveness of DIFSP (introducing of RBI) in tackling the uncertainty (dual uncertainty) existing in the water resources and farmland use management system. Obtained solutions could provide decision makers with the desired schemes under preferable system reliability and economic benefit.

\section{Conclusions}

In this research, a dual-inexact fuzzy stochastic programming (DIFSP) method was proposed through incorporating the random boundary interval (RBI) with fuzzy programming (FP), chance-constrained programming (CCP), and interval linear programming (ILP) techniques. And then the developed method was applied to the water and farmland use planning model (WFUPM) with non-point source pollution mitigation. Overall, this study can (1) conduct comprehensive analysis of water and farmland use management system; (2) tackle multiple uncertainties presented as interval numbers, fuzzy sets, and probability distributions; (3) tackle the correlation exiting between the lower and upper bounds of RBI through the joint probability distribution function, enhancing the stability and robustness of obtained solutions; (4) generate effective schemes including planting area arrangement of crops, water allocations among various end users, water resources supplies, and water pollution control plans under various water supply conditions and system reliabilities; (5) balance the trade-offs between system benefit and failure risks through utilizing the probability of constraint violations and satisfaction degrees; and (6) compare the solutions obtained from ICCP and DIFCCP to demonstrate the application of this developed method for supporting water and farmland use system planning. In the future research, this developed DIFSP method can be applied to other environmental planning problems, and can be incorporated with other optimization technologies to handle various practical issues under uncertainty.

Acknowledgements. This research was supported by the National Science Foundation for Innovative Research Group (no. 51121003), the National Natural Science Foundation of China (no. 51209087), and the special fund of State Key Lab of Water Environment Simulation (11Z01ESPCN).

Edited by: Y. Cai

\section{References}

Azaiez, M. N., Hariga, M., and Al-Harkan, I.: A chance-constrained multi-period model for a special multi-reservoir system, Comput. Oper. Res., 32, 1337-1351, 2005.

Bender, M. J. and Simonovic, S. P.: A fuzzy compromise approach to water resource systems planning under uncertainty, Fuzzy Sets Syst., 115, 35-44, 2000.

Cai, Y. P., Huang, G. H., Nie, X. H., Li, Y. P., and Tan, Q.: Municipal Solid Waste Management Under Uncertainty: A Mixed Interval Parameter Fuzzy-Stochastic Robust Programming Approach, Environ. Eng. Sci., 24, 338-352, 2007.

Cai, Y. P., Huang, G. H., Yang, Z. F., Lin, Q. G., and Tan, Q.: Community-scale renewable energy systems planning under uncertainty - An interval chance-constrained programming approach, Renew. Sustain. Energy Rev., 13, 721-735, 2009a.

Cai, Y. P., Huang, G. H., Tan, Q., and Yang, Z. F.: Planning of community-scale renewable energy management systems in a mixed stochastic and fuzzy environment, Renew. Energy, 34, 1833-1847, 2009b.

Cai, Y. P., Huang, G. H., Tan, Q., and Chen, B.: Identification of optimal strategies for improving eco-resilience to floods in ecologically vulnerable regions of a wetland, Ecol. Model., 222, 360369, 2011.

Cai, Y. P., Huang, G. H., Wang, X., Li, G. C., and Tan, Q.: An inexact programming approach for supporting ecologically sustainable water supply with the consideration of uncertain water demand by ecosystems, Stochast. Environ. Res. Risk Assess., 25, 721-735, 2012.

Canter, L. W., Chawla, M. K., and Swo, C. T.: Addressing trendrelated changes within cumulative effects studies in water resources planning, Environ. Impact Assess. Rev., 44, 58-66, 2014.

Cao, M. F., Huang, G. H., Sun, Y., Xu, Y., and Yao, Y.: Dual inexact fuzzy chance-constrained programming for planning waste management systems, Stochast. Environ. Res. Risk Assess., 24, 1163-1174, 2010.

Castelletti, A., Pianosi, F., and Sessa, R. S.: Integration, participation and optimal control in water resources planning and management, Appl. Math. Comput., 206, 21-33, 2008.

Chen, C. H., Liu, W. L., Liaw, S. L., and Yu, C. H.: Development of a dynamic strategy planning theory and system for sustainable river basin land use management, Sci. Total Environ., 346, 1737, 2005.

Chung, G., Lansey, K., Blowers, P., Brooks, P., Ela, W., Stewart, S., and Wilson P.: A general water supply planning model: Evaluation of decentralized treatment, Environ. Model. Softw., 23, 893-905, 2008.

Dessai, S. and Hulme, M.: Assessing the robustness of adaptation decisions to climate change uncertainties: A case study on water resources management in the East of England, Global Environ. Change, 17, 59-72, 2007.

Deviney Jr., F. A., Brown, D. E., and Rice, K. C.: Evaluation of Bayesian Estimation of a Hidden Continuous-Time Markov Chain Model with Application to Threshold Violation in WaterQuality Indicators, J. Environ. Inf., 19, 70-78, 2012.

Dong, C. L., Schoups, G., and van de Giesen, N.: Scenario development for water resource planning and management: A review, Tech. Forecast. Soc. Change, 80, 749-761, 2013.

Dong, C., Huang, G. H, Tan, Q., and Cai Y. P.: Coupled planning of water resources and agricultural land-use based on an 
inexact-stochastic programming model, Front. Earth Sci., 8, 7080, 2014.

Gregory, R., Failing, L., and Higgins, P.: Adaptive management and environmental decision making: A case study application to water use planning, Ecol. Econ., 58, 434-447, 2006.

Gu, J. J., Huang, G. H., Guo, P., and Shen, N.: Interval multistage joint-probabilistic integer programming approach for water resources allocation and management, J. Environ. Manage., 128, 615-624, 2013.

Guo, P., Huang, G. H., and Li, Y. P.: An inexact fuzzy-chanceconstrained two-stage mixed-integer linear programming approach for flood diversion planning under multiple uncertainties, Adv. Water Resour., 33, 81-91, 2010.

Huang, G. H., Batez, B. W., and Patry, G. G.: A grey linear programming approach for municipal solid waste management planning under uncertainty, Civ. Eng. Syst., 9, 319-335, 1992.

Huang, G. H., Batez, B. W., and Patry, G. G.: Grey integer programming: an application to waste management planning under uncertainty, Eur. J. Oper. Res., 83, 594-620, 1995.

Huang, Y., Li, Y. P., Chen, X., and Ma, Y. G.: Optimization of the irrigation water resources for agricultural sustainability in Tarim River Basin, China, Agric. Water Manage., 107, 74-85, 2012.

Khare, D., Jat, M. K., and Deva, J.: Sunder Assessment of water resources allocation options: Conjunctive use planning in a link canal command, Resour. Conserv. Recycling, 51, 487-506, 2007.

Kondilia, E. and Kaldellis, J. K.: Model development for the optimal water systems planning, Comput. Aided Chem. Eng., 21, 18511856, 2006.

Li, Z., Huang, G., Zhang, Y. M., and Li, Y.P.: Inexact two-stage stochastic credibility constrained programming for water quality management, Resour. Conserv. Recycling, 73, 122-132, 2013.

Lindenschmidt, K. E., Fleischbein, K., and Baborowski, M.: Structural uncertainty in a river water quality modelling system, Ecol. Model., 204, 289-300, 2007.

Lu, H .W., Huang, G. H., Zhang, Y. M., and He, L.: Strategic agricultural land-use planning in response to water-supplier variation in a China's rural region, Agric. Syst., 108, 19-28, 2012.

Mahmoud, M. I., Gupta, H. V., and Rajagopal, S.: Scenario development for water resources planning and watershed management: Methodology and semi-arid region case study, Environ. Model. Softw., 26, 873-885, 2011.
Mehta, V. K., Aslam, O., Dale, L., Miller, N., and Purkey, D. R.: Scenario-based water resources planning for utilities in the Lake Victoria region, Phys. Chem. Earth, 61-62, 22-31, 2013.

Qin, H. P., Su, Q., and Khu, S. T.: An integrated model for water management in a rapidly urbanizing catchment, Environ. Model. Softw., 26, 1502-1514, 2011.

Qin, X. S., Huang, G. H., Zeng, G. M., Chakma, A., and Huang, Y. F.: An interval-parameter fuzzy nonlinear optimization model for stream water quality management under uncertainty, Eur. J. Oper. Res., 180, 1331-1357, 2007.

Ray, D. K., Pijanowski, B. C., Kendall, A. D., and Hyndman, D. W.: Coupling land use and groundwater models to map land use legacies: Assessment of model uncertainties relevant to land use planning, Appl. Geogr., 34, 356-370, 2012.

Riquelme, F. J. M. and Ramos, A. B.: Land and water use management in vine growing by using geographic information systems in Castilla-La Mancha, Spain, Agric. Water Manage., 77, 82-95, 2005.

Satti, S. R., Jacobs, J. M., and Irmak, S.: Agricultural water management in a humid region: sensitivity to climate, soil and crop parameters, Agric. Water Manage., 70, 51-65, 2004.

Sessa, R. S.: Modelling and control for participatory planning and managing water systems, Control Eng. Pract., 15, p. 985, 2007.

Sethi, L. N., Panda, S. N., and Nayak, M. K.: Optimal crop planning and water resources allocation in a coastal groundwater basin, Orissa, India, Agric. Water Manage., 83, 209-220, 2006.

Tan, Q., Huang, G. H., and Cai, Y. P.: Radial interval chanceconstrained programming for agricultural non-point source water pollution control under uncertainty, Agric. Water Manage., 98, 1595-1606, 2011.

Victoria, F. B., Filho, J. S. V., Pereira, L. S., Teixeira, J. L., and Lanna, A. E.: Multi-scale modeling for water resources planning and management in rural basins, Agric. Water Manage., 77, 420, 2005.

Zarghami, M. and Hajykazemian, H.: Urban water resources planning by using a modified particle swarm optimization algorithm, Resour. Conserv. Recycling, 70, 1-8, 2013

Zhang, Y. M., Huang, G. H., and Zhang, X. D.: Inexact de Novo programming for water resources systems planning, Eur. J. Oper. Res., 199, 531-541, 2009. 